Bull. Mater. Sci., Vol. 17, No. 6, November 1994, pp. 1029-1037. (C Printed in India.

\title{
EXAFS and MAS NMR studies of sodium molybdophosphate and sodium tungstophosphate glasses
}

\author{
S MUTHUPARI, G U KULKARNI ${ }^{\dagger}$ and $\mathrm{K}$ J RAO* \\ Materials Research Centre, Indian Institute of Science, Bangalore 560 012, India \\ ${ }^{\dagger}$ Present address: Department of Chemistry, University of Wales, P.O. Box 912, Cardiff \\ CF1 3TB, UK
}

\begin{abstract}
The local order around molybdenum and tungsten atoms in various sodium molybdophosphate and sodium tungstophosphate glasses has been investigated using extended $X$-ray absorption fine structure (EXAFS). Both molybdenum and tungsten atoms are present in six-coordinated environment in these glasses. Magic angle spinning nuclear magnetic resonance (MAS NMR) of ${ }^{31} \mathrm{P}$ suggests that metaphosphate or neutral $\left[\mathrm{POO}_{3 / 2}\right]$ groups are present in these glasses.
\end{abstract}

Keywords. EXAFS; MAS NMR; molybdophosphate glasses; tungstophosphate glasses.

\section{Introduction}

Transition metal oxides $\mathrm{WO}_{3}$ and $\mathrm{MoO}_{3}$ do not form glasses even when their melts are quenched at high rates. However they easily form binary glasses over a wide range of compositions in combination with conventional glass forming oxides like $\mathrm{B}_{2} \mathrm{O}_{3}$ and $\mathrm{P}_{2} \mathrm{O}_{5}$. Transport, optical, elastic and spectroscopic properties of these glasses have been investigated by a number of workers (Linsey et al 1970; Magistris et al 1983; Selvaraj and Rao 1985; Bridge and Patel 1986; Kobayashi et al 1987; Damodaran and Rao 1989; Chowdari et al 1990; Morgan and Magruderh 1990; Gohar 1993; Muthupari and Rao 1994; Muthupari et al 1994). In recent years alkali molybdophosphates and alkali tungstophosphate glasses have attracted attention because of their electronic properties and high ionic conductivity. From the studies conducted in this laboratory earlier a model has been proposed for binary $\mathrm{MO}_{3}-\mathrm{P}_{2} \mathrm{O}_{5}$ (M-Mo or W) glasses in which corner sharing $\left[\mathrm{MO}_{6 / 2}\right]$ octahedral and $\left[\mathrm{POO}_{3 / 2}\right]$ tetrahedral units (Selvaraj and Rao 1985; Damodaran and Rao 1989) are considered as building blocks of glass structure. The three-dimensional network structure of these glasses is modified by the incorporation of alkali oxides and at high concentration of alkalies, even discrete $\left[\mathrm{MO}_{4}\right]^{2-}$ ions are produced (Selvaraj and Rao 1985; Znasik and Jamnicky 1992). It is possible to obtain the local structural information around $M o$ or $W$ atoms from EXAFS analysis and around $P$ atoms using MAS NMR studies. Even though there are many reports on the thermal, IR, transport, elastic and optical studies, EXAFS (Studer et al 1986) and MAS NMR studies are few (Prabakar et al 1987). In this paper we report EXAFS and MAS NMR studies on a range of sodium molybdophosphate and sodium tungstophosphate glasses. The structure of the glasses have been discussed in the light of the model proposed for these glasses earlier from this laboratory (Selvaraj and Rao 1985).

*For correspondence. 


\section{Experimental}

Sodium molybdophosphate and sodium tungstophosphate glasses of several compositions have been prepared starting from analar grade $\mathrm{Na}_{2} \mathrm{CO}_{3}$ (BDH), $\left(\mathrm{NH}_{4}\right)_{2} \mathrm{HPO}_{4}(\mathrm{BDH}),\left(\mathrm{NH}_{4}\right)_{6} \mathrm{Mo}_{7} \mathrm{O}_{24} 4 \mathrm{H}_{2} \mathrm{O}$ (E-Merck) and $\mathrm{WO}_{3}$ (Cerac Inc.). Required quantities of the above materials were thoroughly mixed and heated in a platinum crucible to $673 \mathrm{~K}$ in an electrically heated muffle furnace for several hours in order to remove $\mathrm{H}_{2} \mathrm{O}, \mathrm{NH}_{3}$ and $\mathrm{CO}_{2}$. The samples were then melted and held at temperatures of $1100 \mathrm{~K}-1500 \mathrm{~K}$ for $30 \mathrm{~min}$ and quenched between two stainless steel plates. The compositions of the glasses are given in table 1 . The glasses are grouped into three series: CM (or CW), CN and MP (or WP) depending on the nature of substitution for convenience. The series $\mathrm{CN}$ and $\mathrm{CM}$ (or $\mathrm{CW}$ ) represent compositions where $\mathrm{Na}_{2} \mathrm{O}$ and $\mathrm{MoO}_{3}$ (or $\mathrm{WO}_{3}$ ) are kept constant. The MP (or WP) series represents pseudobinary compositions of $\mathrm{MoO}_{3}$ (or $\mathrm{WO}_{3}$ ) and $\mathrm{P}_{2} \mathrm{O}_{5}$.

Table 1. Structural parameters derived from Mo-K and W-Lin EXAFS of molybdophosphate and tungstophosphate glasses.

\begin{tabular}{|c|c|c|c|c|}
\hline $\begin{array}{l}\text { Glass } \\
\text { number }\end{array}$ & $\begin{array}{c}\text { Composition } \\
(m o l \text { \%) } \\
\mathrm{Na}_{2} \mathrm{O}: \mathrm{MoO}_{3}: \mathrm{P}_{2} \mathrm{O}_{5}\end{array}$ & $\begin{array}{l}\text { Coordination } \\
\text { no. }(M)\end{array}$ & $\stackrel{r}{(A)}$ & $\Delta \sigma^{2}$ \\
\hline \multicolumn{5}{|l|}{$\mathbf{C M}$} \\
\hline 451 & $40: 50: 10$ & $6 \cdot 1$ & 1.73 & 0.0006 \\
\hline 154 & $10: 50: 40$ & 6.3 & 1.71 & 0.0015 \\
\hline \multicolumn{5}{|l|}{$\mathrm{CN}$} \\
\hline 451 & $40: 50: 10$ & 6.1 & 1.73 & 0.0006 \\
\hline 442 & $40: 40: 20$ & 6.4 & 1.71 & 0.0008 \\
\hline 424 & $40: 20: 40$ & 6.3 & 1.71 & 0.0010 \\
\hline \multicolumn{5}{|l|}{ MP } \\
\hline MP2 & $-: 80: 20$ & $6 \cdot 2$ & 1.71 & - \\
\hline MP4 & $-: 60: 40$ & $6 \cdot 4$ & 1.70 & - \\
\hline \multicolumn{5}{|c|}{$\mathrm{Na}_{2} \mathrm{O}: \mathrm{WO}_{3}: \mathrm{P}_{2} \mathrm{O}_{5}$} \\
\hline 451 & $40: 50: 10$ & $\begin{array}{l}5.2 \\
1.0\end{array}$ & $\begin{array}{l}1.76 \\
2.21\end{array}$ & $\begin{array}{l}0.0001 \\
0.0001\end{array}$ \\
\hline 352 & $30: 50: 20$ & $\begin{array}{l}3.2 \\
2.8\end{array}$ & $\begin{array}{l}1.76 \\
2.23\end{array}$ & $\begin{array}{l}0.0015 \\
0.0015\end{array}$ \\
\hline \multicolumn{5}{|l|}{$\mathrm{CN}$} \\
\hline 451 & $40: 50: 10$ & $\begin{array}{l}5.2 \\
1.0\end{array}$ & $\begin{array}{l}1.76 \\
2.21\end{array}$ & $\begin{array}{l}0.0001 \\
0.0001\end{array}$ \\
\hline 442 & $40: 40: 20$ & $\begin{array}{l}3.2 \\
2.8\end{array}$ & $\begin{array}{l}1.73 \\
2.19\end{array}$ & $\begin{array}{l}0.001 \\
0.003\end{array}$ \\
\hline 424 & $40: 20: 40$ & $\begin{array}{l}3 \cdot 1 \\
2.9\end{array}$ & $\begin{array}{l}1.74 \\
2 \cdot 19\end{array}$ & $\begin{array}{l}0.002 \\
0.002\end{array}$ \\
\hline \multicolumn{5}{|l|}{ WP } \\
\hline WP2 & $-: 80: 20$ & $\begin{array}{l}5.7 \\
0.4\end{array}$ & $\begin{array}{l}1 \cdot 74 \\
2 \cdot 17\end{array}$ & $\begin{array}{c}0.0005 \\
0.000\end{array}$ \\
\hline WP4 & $-: 60: 40$ & $\begin{array}{l}3.1 \\
2.9\end{array}$ & $\begin{array}{l}1 \cdot 74 \\
2 \cdot 17\end{array}$ & $\begin{array}{l}0.0013 \\
0.0013\end{array}$ \\
\hline
\end{tabular}


EXAFS associated with $\mathrm{K}$-edge of Mo, Mo-K and $\mathrm{L}_{\mathrm{III}}$-edge of $\mathrm{W}, \mathrm{W}-\mathrm{L}_{\text {III }}$ were recorded using a Rigaku spectrometer with a rotating anode $\mathrm{X}$-ray generator (Ru-200B, Rigaku, Japan) at room temperature. For Mo K EXAFS, a Ge (440) crystal was used as a monochromator with $0.1 \mathrm{~mm}$ slit for $\mathrm{X}$-rays from a $\mathrm{Cu}$ target. The spectral resolution is $7 \mathrm{eV}$ at $20 \mathrm{keV}$ incident energy. W $\mathrm{L}_{\mathrm{II}}$ EXAFS was recorded using a Ge (330) monochromator and Mo target. The slit width used is $0.2 \mathrm{~mm}$. The EXAFS of the glasses were recorded with self supporting thin pellets of glass samples. The thickness of the pellets were adjusted so that the extinction value jumped by a factor of 2 at the absorption edge in all cases. EXAFS of the reference compounds, $\mathrm{CaMoO}_{4}$ and $\mathrm{CaWO}_{4}$, were also recorded under the same conditions. The EXAFS data was treated using a multiphasic model involving additive relationship of EXAFS function (Kulkarni et al 1989). The Fourier transforms of EXAFS data were obtained with $k_{\min }=4$ and $k_{\max }=12 \AA^{-1}$ for both Mo K and W $L_{\text {III }}$ edges after weighing the EXAFS data by $k^{3}$.

${ }^{31} \mathrm{P}$ MAS NMR spectra were recorded using a bruker MSL 300 solid state high resolution spectrometer operating at a $121.495 \mathrm{MHz}$ with a magnetic field of 7.05 Tesla. A $90^{\circ}$ pulse with a duration of $5 \mu \mathrm{sec}$ and a pulse delay of $5 \mathrm{sec}$ was employed. A cylindrical zirconia rotor with a spinning speed of $3000-4000 \mathrm{~Hz}$ was used in all experiments. The chemical shift values are given with respect to ${ }^{31} \mathrm{P}$ signals from $85 \% \mathrm{H}_{3} \mathrm{PO}_{4}$ used as a reference material (negative shifts are due to high field).

\section{Results and discussion}

In these experiments, we have examined the structure around Mo or $W$ using EXAFS while the structure around $P$ were examined using ${ }^{31} P$ MAS NMR. We discuss below in separate sections the EXAFS and MAS NMR results.

\subsection{EXAFS of Mo-K and $W-L_{I I I}$ absorptions}

The Fourier transforms of Mo $\mathbf{K}$ edge of the molybdophosphate glasses (the radial distribution functions) are shown in figure 1. The Fourier transforms are similar for all the glasses with a prominent peak at $1.72 \AA$ which corresponds to Mo-O distance. Inverse Fourier transforms of the radial distribution functions with various $\mathbf{R}$ windows were performed and curve fitted using phase and amplitude parameters obtained from $\mathrm{CaMoO}_{4}(N=4$ and $r=1.76 \AA$, where. $N$ is the coordination number and $r$ the distance between Mo and $O$ atoms). The results are summarized in table 1. Figure 2 shows the Fourier transforms of EXAFS associated with $W L_{\text {III }}$ edge in tungstophosphate glasses. The inverse transforms of the radial distribution functions for $R$ windows $(1-2 \AA)$ were carried out employing the phase and amplitude parameters of the $\mathrm{W}-\mathrm{O}$ in $\mathrm{CaWO}_{4}(N=4$ and $r=1.78 \AA)$. The results are presented in table 1. From figure 1 and table 1 , it is evident that the oxygen coordination $(N)$ around Mo and the first neighbour Mo-O distances are nearly identical for all compositions. However, W $\mathrm{L}_{\mathrm{III}}$ EXAFS results show a slightly different trend. Unlike in the molybdophosphate glasses, the first coordination $(\mathrm{W}-\mathrm{O})$ peak exhibits a split feature in several compositions. Splitting indicates the presence of a two-subshell structure of oxygen coordination around tungsten atoms. The distances 


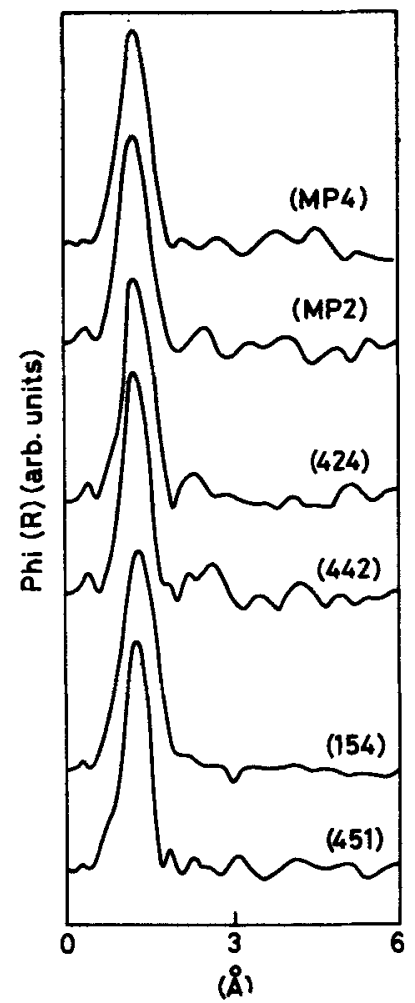

Figure 1. Fourier transforms of the Mo-K EXAFS of molybdophosphate glasses. The glass numbers are indicated in the parenthesis on the right side of each spectrum. (Refer table 1 for compositions).

W-O from the two oxygen subshells are 1.75 and $2.25 \AA$ respectively. Only the low $\mathrm{P}_{2} \mathrm{O}_{5}$ containing glasses (glasses WP2 and 451) exhibit a single peak nature like in molybdophosphate glasses. But in both molybdophosphate and tungstophosphate glasses, the disorder parameter $\Delta \sigma^{2}$ increases with $\mathrm{P}_{2} \mathrm{O}_{5}$ content in all the series except in MP.

From these results, it can be seen that the coordination number of both Mo and $\mathrm{W}$ atoms are 6 indicating that these atoms are likely to be present in octahedral positions. Thus it provides strong support to the structural model of molybdophosphate and tungstophosphate glasses proposed earlier from this laboratory. Briefly, according to this structural model, molybdophosphate and tungstophosphate glasses consist of corner sharing $\left[\mathrm{MO}_{6 / 2}\right]$ octahedra and $\left[\mathrm{POO}_{3 / 2}\right]$ tetrahedra. When alkali oxide is added, the glass network is modified and structural units such as $\left[\mathrm{MO}_{5 / 2} \mathrm{O}^{-}\left(\equiv \mathrm{M}_{1}\right)\right.$, $\left[\mathrm{MOO}_{4 / 2}\right]^{2-}\left(\equiv \mathrm{M}_{2}\right),\left[\mathrm{POO}_{2 / 2} \mathrm{O}\right]^{-}\left(\equiv \mathrm{P}_{1}\right)$ and discrete anions like $\left[\mathrm{MO}_{4}\right]^{2-}\left(\equiv \mathrm{M}_{2}^{\prime}\right)$ are created. In spite of the lower connectivities of the latter structural entities, the coordination of Mo (or $W$ ) remains the same, i.e. 6, except in discrete anions, $M_{2}^{\prime}$. This is clearly borne out from the present studies of Mo-K and $W-L_{I I I}$ EXAFS. However the presence of two-oxygen subshell structure in high $\mathrm{P}_{2} \mathrm{O}_{5}$ containing tungstate glasses with two $\mathrm{W}-\mathrm{O}$ nearest neighbour distances of $1.75 \AA$ and $2.20 \AA$ respectively is a reflection of the tetrahedral distortion of $\left[\mathrm{WO}_{6}\right]$ octahedra resulting 


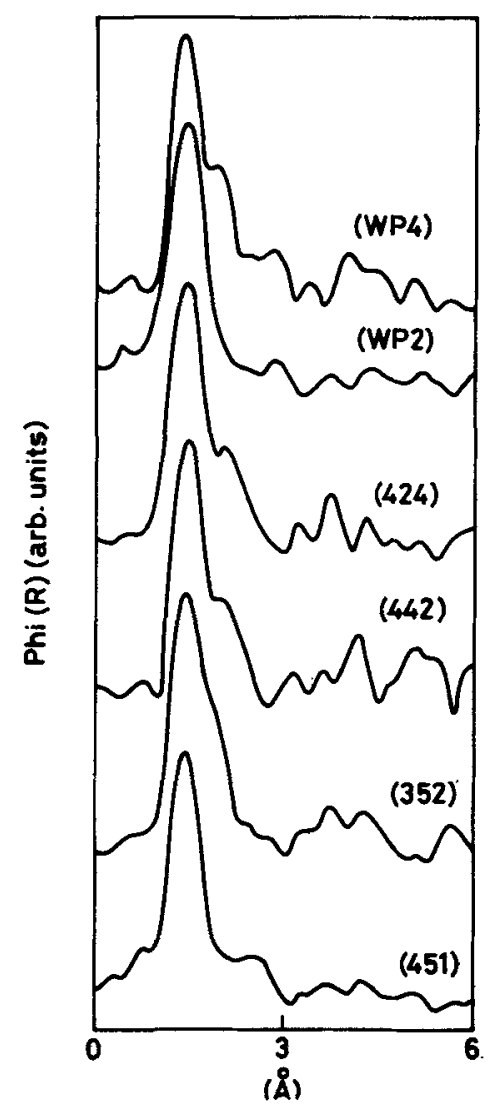

Figure 2. Fourier transforms of the W Lin EXAFS of tungstophosphate glasses. (Refer table 1 for compositions).

in two different $\mathrm{W}-\mathrm{O}$ bond lengths. Pulsed neutron studies on alkali tungstate glasses and IR studies on tungstophosphate glasses have also shown that (Selvaraj and Rao 1985; Kobayashi et al 1987) two different W-O bond lengths are present in the glass network.

In the highly modified, high $\mathrm{P}_{2} \mathrm{O}_{5}$ containing glasses the following bond switching reaction is envisaged in the model.

$$
-\mathrm{P}-\mathrm{O}-\mathrm{M}_{2}-\mathrm{O}-\mathrm{P}-\rightleftharpoons \mathrm{M}_{2}^{\prime}+-\mathrm{P}-\mathrm{O}-\mathrm{P}-
$$

or equivalently,

$$
\left[\mathrm{MO}_{4 / 2} \mathrm{O}_{2}\right]^{2-} \rightleftharpoons\left[\mathrm{MO}_{4}\right]^{2-}
$$

The $\mathrm{M}_{2} \rightarrow \mathrm{M}_{2}^{\prime}$ conversion is expected to be aided by both higher concentration of alkalies and presence of more -P-O-P- linkages. In such glasses (for e.g. glasses CN433 and CN424 in table 2), one can expect the presence of $\mathrm{M}_{2}^{\prime}$ units. Both elastic properties and infrared spectroscopic studies indicate the presence of $\mathbf{M}_{2}^{\prime}$ 
Table 2. ${ }^{31}$ P MAS NMR data of molybdophosphate and tungstophosphate glasses.

\begin{tabular}{|c|c|c|c|c|c|}
\hline \multicolumn{3}{|c|}{ Molybdate glasses } & \multicolumn{3}{|c|}{ Tungstate glasses } \\
\hline $\begin{array}{l}\text { Glass } \\
\text { no. }\end{array}$ & $\begin{array}{c}\delta \\
(\mathrm{ppm})\end{array}$ & $\begin{array}{c}\text { FWHM } \\
\text { (ppm) }\end{array}$ & $\begin{array}{c}\text { Glass } \\
\text { no. }\end{array}$ & $\begin{array}{c}\delta \\
(\mathrm{ppm})\end{array}$ & $\begin{array}{c}\text { FWHM } \\
\text { (ppm) }\end{array}$ \\
\hline $\mathbf{C M}$ & & & $C W$ & & \\
\hline 451 & 6.6 & 10.5 & 451 & 8.91 & 9.2 \\
\hline 352 & $1 \cdot 1$ & 11.9 & 352 & 9.0 & $18 \cdot 3$ \\
\hline 253 & -6.6 & $16 \cdot 4$ & 253 & $12 \cdot 7$ & 24.8 \\
\hline 154 & $-15 \cdot 5$ & 20.9 & 154 & 14.9 & 29.5 \\
\hline $\mathrm{CN}$ & & & $\mathrm{CN}$ & & \\
\hline 451 & $6 \cdot 6$ & 10.5 & 451 & 8.9 & 9.2 \\
\hline 442 & 4.7 & 13.4 & 442 & 9.3 & 10.9 \\
\hline 433 & -3.7 & 14.9 & 433 & 11.9 & $12 \cdot 2$ \\
\hline 424 & $-6,-17.8$ & - & 424 & $-8,-17.8$ & - \\
\hline $\mathbf{M P}$ & & & WP & & \\
\hline MP2 & -9.2 & 12.7 & - & - & - \\
\hline MP3 & -10.8 & $22 \cdot 3$ & WP3 & -12.0 & 9.7 \\
\hline MP4 & -15.4 & 26.8 & WP4 & -13.5 & 11.9 \\
\hline MP5 & $-17 \cdot 3$ & - & WP5 & -13.5 & $12 \cdot 3$ \\
\hline
\end{tabular}

type of structural units along with other units such as $M_{1}, M_{2}$ and $P_{1}$ in the highly modified high $\mathrm{P}_{2} \mathrm{O}_{5}$ glasses (Selvaraj and Rao 1985; Damodaran and Rao 1989; Muthupari et al, unpublished results). In EXAFS we should expect the formation of $\mathrm{M}_{2}^{\prime}$ units to be reflected in a slight decrease of average coordination number only. However the uncertainties $( \pm 10 \%)$ in the determination of $N$ prevents clear identification of the presence of $\mathbf{M}_{2}^{\prime}$ units in the dominating concentration of other units possessing coordination of six oxygens.

\section{$3.2{ }^{31} P$ MAS NMR studies}

Typical ${ }^{31} \mathrm{P}$ MAS NMR spectra of molybdophosphate and tungstophosphate glasses are shown in -figure 3 . The chemical shifts and the full width at half maxima (FWHM) obtained from these spectra for all the glasses are given in table 2. All the glasses exhibit a single resonance peak except the glass 424 , which exhibits two resonance peaks. In all the series, with increasing $\mathrm{P}_{2} \mathrm{O}_{5}$ content, the chemical shifts shift to lower values. FWHM values are indicative of the extent of disorder in the material. FWHM values almost uniformly increase with increasing $\mathrm{P}_{2} \mathrm{O}_{5}$ in both molybdophosphate and tungstophosphate glasses suggesting that greater disorder is introduced into the glass structure when the $\mathrm{P}_{2} \mathrm{O}_{5}$ content is increased. This increase in the disorder may be attributed to two reasons: (i) alterations of the chemical nature of the tetrahedra around phosphorous due to the formation of $P_{1}$ units and (ii) the increased complexity of the second neighbour environment of phosphorous due to the formation of units like $M_{1}, M_{2}$ and $M_{2}^{\prime}$. In simple binary MP and WP glasses it is clearly due to the variation in the number of $\left[\mathrm{MO}_{6 / 2}\right]$ and $\left[\mathrm{POO}_{3 / 2}\right]$ units surrounding any $\left[\mathrm{POO}_{3 / 2}\right]$ units. The flexibility of $\mathrm{P}-\mathrm{O}-\mathrm{P}$ angles being higher than $\mathrm{P}-\mathrm{O}-\mathrm{M}$ angles ( $\mathrm{M}$ is in an octahedron) and produces a greater 


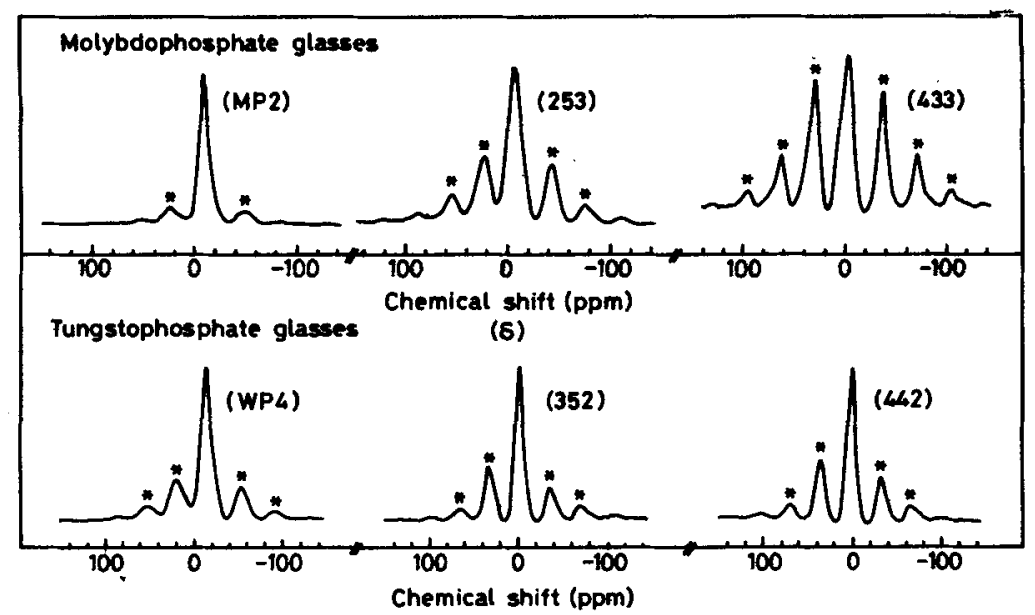

(6)

Figure 3. Typical ${ }^{31} \mathrm{P}$ MAS NMR spectra of few molybdophosphate and tungstophosphate glasses. Spinning side bands are marked with asterisks. The compositions are identified by their respective numbers in table 2 .

spread of second neighbour environment in $\mathrm{P}_{2} \mathrm{O}_{3}$ rich glasses. Correspondingly $\Delta \sigma^{2}$, disorder parameter is high in high $\mathrm{P}_{2} \mathrm{O}_{5}$ containing glasses.

In an earlier MAS NMR investigation (Prabakar et al 1987) on phosphate glasses, it was shown that the dominant species in the phosphate glasses is always the metaphosphate units, because these polymerize to give rise to chains.<smiles>CCC(C)(C)OP(=O)([O-])OC</smiles>

Correspondingly the MAS NMR signal from all phosphate glasses (Prabakar et al 1987) generally fall into a separate phase field characterized by a parameter, $\left(Z_{\text {eff }} l r\right) \times q>0$ on the abscissa and ${ }^{31} \mathrm{P}$ chemical shifts values generally $<20 \mathrm{ppm}$. Here, $Z_{\text {eff }}$ represents the charge on the cation wherever it is present; otherwise it refers to the partial charge on the molybdenum or tungsten, $r$ is the ionic radius of the cation (referred to the most common coordination number) and $q$ the partial charge on the phosphorous atom calculated using the Sanderson's procedure (Sanderson 1983). The parameter has the units of energy. In figure 4, the phase field is reproduced from our earlier work (Prabakar et al 1987) and the data pertaining to the present glasses are marked which provides additional evidence to the presence of only $P$ or $P$, units in the glasses.

It was mentioned earlier that $\left[\mathrm{MO}_{6 / 2}\right]$ octahedra and $\left[\mathrm{POO}_{3 / 2}\right]$ tetrahedra are corner connected in the formation of these glass structures. Further the model also assumes that the network is chemically ordered, i.e. like unit connections (M-M or P-P) which appear only when either $\mathbf{M}$ or $\mathbf{P}$ is in stoichiometric excess. Modification 


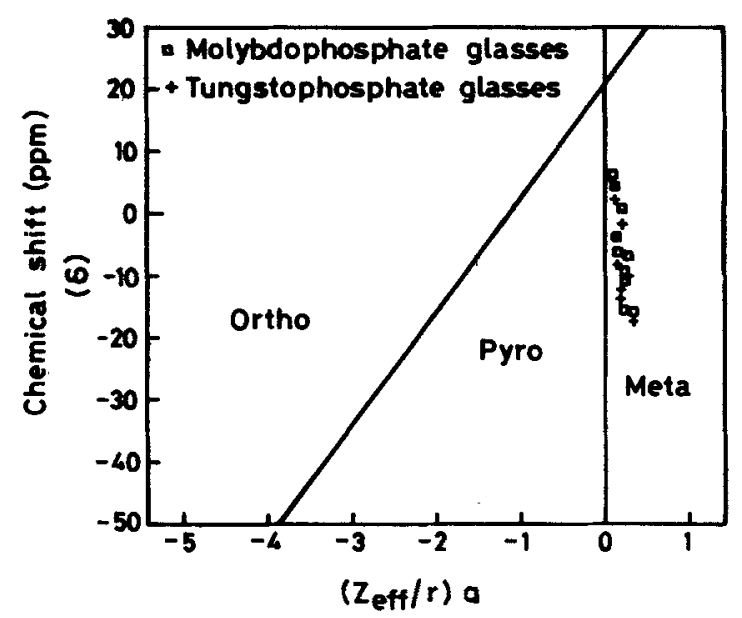

Figure 4. Plot of ${ }^{31} \mathrm{P}$ chemical shifts of molybdophosphate and tungstophosphate glasses vs $\left(Z_{\text {eff }} r\right) \times q$.

Table 3. Mole fractions of different kinds of structural species present in the glasses. (In fractions; alkali fractions not included).

\begin{tabular}{lccllc}
\hline Glass & \multicolumn{5}{c}{ Species } \\
\cline { 2 - 6 } no. & $M$ & $M_{1}$ & $M_{2}$ & $P$ & $P_{1}$ \\
\hline 154 & 0.277 & - & 0.0692 & 0.554 & - \\
253 & 0.218 & - & 0.145 & 0.436 & - \\
352 & 0.156 & - & 0.233 & 0.311 & - \\
451 & 0.085 & - & 0.343 & 0.172 & - \\
442 & - & 0.15 & 0.15 & 0.15 & 0.15 \\
433 & - & 0.133 & 0.066 & 0.133 & 0.266 \\
424 & - & - & 0.12 & 0.24 & 0.24 \\
MP2 & 0.66 & - & - & 0.34 & - \\
MP3 & 0.538 & - & - & 0.462 & - \\
MP4 & 0.482 & - & - & 0.572 & -
\end{tabular}

Where $\mathrm{M}=\left[\mathrm{MO}_{6 / 2}\right] ; \quad \mathrm{M}_{1}=\left[\mathrm{MO}_{5 / 2} \mathrm{O}^{-} ; \quad \mathrm{M}_{2}=\left[\mathrm{MO}_{4 / 2} \mathrm{O}_{2}\right]^{2-}\right.$; $\mathrm{P}=\left[\mathrm{POO}_{32}\right] ; \mathrm{P}_{1}=\left[\mathrm{POO}_{2} \mathrm{O}^{-}\right.$

of such network by an alkali oxide occurs by hierarchical bond breaking in the order of their bond energies of linkages, $E_{\mathrm{MOM}}<E_{\mathrm{MOP}}<E_{\mathrm{POP}}$. Hence the MOM linkage will be modified first, and then MOP and finally the POP linkage will be modified (Selvaraj and Rao 1985). In fact this is well supported from a consideration of partial charges calculated on the basis of molecular electronegativities as shown elsewhere (Muthupari et al, unpublished results). Using such hierarchical bond breaking order, different structural results such as $M_{1}, M_{2}$ and $P_{1}$ are evaluated in such glasses and listed in table 3.

From table 3, it can be seen that the glasses studied contain neither ortho nor pyrophosphate units but only either neutral $\left[\mathrm{POO}_{3 / 2}\right]$ or metaphosphate groups. Table 3 also confirms that $\left[\mathrm{MO}_{6 / 2}\right], M_{1}$ and $M_{2}$ units dominate the structure and any 
$M_{2}^{\prime}$ units formed can only be in low concentrations and therefore not observed in EXAFS.

\section{Conclusions}

EXAFS and MAS NMR studies on the sodium molybdophosphate and sodium tungstophosphate glasses reveal that the structure is made up of $\left[\mathrm{MO}_{6 / 2}\right]$ octahedra and $\left[\mathrm{POO}_{3 / 2}\right]$ tetrahedra which are modified by the addition of alkali oxide. EXAFS results show that both the transition metal atoms (Mo and $W$ ) are present in 6 coordinated environment. MAS NMR results indicate the presence of metaphosphate or neutral $\left[\mathrm{POO}_{3 / 2}\right]$ groups in the glass network.

\section{Acknowledgements}

Thanks are due to Prof. C N R Rao FRS, for his kind encouragement. Authors also thank Dr S Lakshmi Raghavan for critical reading of the manuscript and $\mathrm{Mr}$ $P T$ Wilson for his help in recording the MAS NMR spectra. One of the authors (SM) thanks the European community for financial assistance.

\section{References}

Bridge B and Patel N D 1986 J. Mater. Sci. 211187

Chowdari B V R, Tan K L, Chia W T and Gopalakrishna R 1990 Solid State Ionics $40 / 41684$

Damodaran K V and Rao K J 1989 J. Am. Ceram. Soc. 72533

Gohar I A 1933 Phys. Chem. Glasses 34117

Kobayashi S, Misawa M and Suzuki K 1987 J. Non-Cryst. Solids 91180

Kulkarni G U, Sankar G and Rao C N R 1989 Z. Phys. B73 529

Linsey A S, Owen A E and Hayatee F M 1970 J. Non-Cryst. Solids 4208

Magistris A, Chiodelli $G$ and Duclot M 1983 Solid State lonics 9611

Morgan S H and Magruderh R H $1990 \mathrm{~J}$. Am. Ceram. Soc. 73753

Muthupari S and Rao K J 1994 Chem. Phys. Lett. 223133

Muthupari S, Prabakar S and Rao K J 1994 J. Phys. Chem. 982646

Muthupari S, Lakshmi Raghavan S and Rao K J (unpublished results)

Prabakar S, Rao K J and Rao C N R 1987 Chem. Phys. Lets. 13996

Sanderson R T 1983 Polar cavalence (New York: Academic Press)

Selvaraj U and Rao K J 1985 J. Non-Cryst. Solids 72315

Studer F, Lebail A and Raveau B $1986 \mathrm{~J}$. Solid Stute Chem. 63414

Znasik P and Jamnicky M 1992 J. Non-Cryst. Solids 14674 